5. Rudan I, Boschi-Pinto C, Biloglav Z, Mulholland K, Campbell H (2008), Epidemiology and etiology of childhood pneumonia, Bull World Health Organ, 86(5), pp. 408-16.

6. Yang J-x, Zhang M, Liu Z-h, et al. (2009),
Detection of lung atelectasis/consolidation by ultrasound in multiple trauma patients with mechanical ventilation, 1(1), pp. 13-16.

7. Châu NQ, Bệnh học nội khoa tâp I. 2012, NXB Y học Hà Nội: Trường Đại học Y Hà Nội. tr. 14-27.

\title{
ĐẶC ĐIỂM LÂM SÀNG VÀ TÌNH HÌNH ĐIỀU TRI ĐAU THẮT LƯNG TAI PHÒNG CHÂM CỨU NGOAI TRÚ BỆNH VIÊ̂N ĐA KHOA Y HỌC CỔ TRUYỀn HÀ NộI
}

\author{
Nguyễn Thị Thanh Tú*, Cao Thị Huyền Trang*, Nhữ Thị Thảo*
}

\section{TÓM TẮT}

Mục tiêu: Khảo sát đặc điểm lâm sàng và tình hình điều trị bệnh đau thắt lưng tại phòng Châm cứu ngoại trú - Bệnh viện Đa khoa Y học cổ truyền Hà Nội. Đối tượng và phương pháp: Nghiên cứu tiến cứu, mô tả cắt ngang. Chọn tất cả các bệnh nhân đau thắt lưng vào điều trị ngoại trú từ tháng 01/2019 đến tháng 09/2019. Kết quả: Trong thời gian nghiên cứu, phòng Châm cứu ngoại trú Bệnh viện Đa khoa đã điều trị cho 150 bệnh nhân. Về đặc điểm lâm sàng: bệnh nhân tập trung ở độ tuổi 30 - $39(34 \%)$, đa phần là nữ giới $(64,0 \%)$, lao động trí óc $(58,0 \%)$, thời gian mắc bệnh chủ yếu < 4 tuần $(72,0 \%)$, bệnh thường xuất hiện sau thay đổi thời tiết $(51,33 \%)$. Sau quá trình điều tri, số bênh nhân đõ chiếm tỉ lệ cao $(70 \%)$ và không có bệnh nhân nào nặng thêm. Kết luận: Nghiên cứu đã cung cấp những thông tin liên quan đến đặc điểm lâm sàng và tình hình điều trị bệnh ĐTL, giúp lẳnh đao phòng nhìn nhân tổng quát, đầy đủ vế bệnh để có thể đa dạng hơn các phương pháp điều trị cững như nâng cao hiệu quả điều trị.

Tư khóa: Đau thắt lưng, đặc điểm lâm sàng, tình hình điều trị

SUMMARY

CLINICAL CHARACTERISTICS AND

TREATMENT SITUATION OF LOW BACK

PAIN DISEASE AT THE OUTPATIENT

ACUPUNCTURE CLINIC - HANOI GENERAL

HOSPITAL OF TRADITIONAL MEDICINE

Objectives: To analyze the clinical characteristics and the treatment situation of the low back pain disease at the Outpatient acupuncture clinic, Hanoi General Hospital of Trditional Medicine. Subjects and Methods: Prospective cross-sectional study. Enrolled all patients admitted to the Outpatient clinic from January to September 2019. Results: In the study duration, the outpatient acupuncture clinic treated 150 low back pain patients. For the clinical characteristics:

*Trường Đại học Y Hà Nội

Chịu trách nhiệm chính: Nguyễn Thị Thanh Tú

Email: thanhtu@hmu.edu.vn

Ngày nhận bài: 2.3.2021

Ngày phản biên khoa học: 27.4.2021

Ngày duyệt bài: 11.5.2021
$34 \%$ of the patients in our study aged from $30-39$, $64 \%$ were female, $58 \%$ worked in the manual labor fields, most of whom had the durations of this disease less than 4 weeks (72\%), thí disease ususally occurred when the climate changed $(51,33 \%)$. After treatment, $70 \%$ of the patients had improved outcomes, no patients had worse outcome. Conclusions: This study has provided the information relating to the clinical characteristics and the treatment situation of the low back pain disease. These results help the managers to diversify the treatment therapies, enhancing the treatment results.

Keywords: low back pain, clinical, treatment

\section{I. ĐĂT VẤN ĐỀ}

Đau thắt lưng (ĐTL) hay còn gọ là đau lưng vùng thấp (Low back pain) là hội chứng đau khu trú trong khoảng từ ngang mức L1 đến nếp lằn mông [4]. Đây là một hội chứng xương khớp hay găp nhất trong thực hành lâm sàng. Nghiên cứu phỏng vấn sức khỏe quốc gia Hoa Kỳ năm 2002 cho thấy $26,4 \%$ trong số 30.000 người tham gia đã trải qua ít nhất một ngày đau lưng trong thời gian 3 tháng. Tại Việt Nam, tỷ lệ ĐTL chiếm 12\% trong nhân dân, chiếm 17\% những người trên 60 tuổi; chiếm 6\% tổng số các bệnh xương khớp [1]. Theo thống kê năm 2016 - 2017, tại phòng Châm cứu ngoại trú bệnh viện Đa khoa YHCT Hà Nội tỉ lệ bệnh nhân ĐTL đến điều trị đứng thứ 2 trong số các bệnh được điều trị [3]. Với mong muốn có cái nhìn tổng quát về bệnh nhân đau thắt lưng, từ đó đưa ra các phương pháp điều trị có hiệu quả hơn nữa, chúng tôi tiến hành nghiên cứu đề tài với hai mục tiêu sau:

1. Khảo sát đặc điểm lâm sàng của bệnh nhân đau thắt lưng điều trị tại phòng Châm cứu ngoại trú - Bv Đa khoa Y hoc cổ truyền Hà Nôii.

2. Khảo sát tình hinh điều trị đau thắt lưng tại phòng Châm cứu ngoại trú - Bệnh viện Đa khoa Y học cổ truyền Hà Nội.

\section{II. ĐỐI TƯợNG VÀ PHƯƠNG PHÁP NGHIÊN CỨU 2.1. Đối tượng nghiên cứu \\ + Tiêu chuẩn lựa chọn: Bệnh nhân được}


chẩn đoán ĐTL, tự nguyện tham gia nghiên cứu, không phân biệt giới tính; tuổi $\geq 16$ tuổi, không có các dấu hiệu tổn thương thần kinh, nhận thức, ảnh hưởng tới việc trả lời hoàn thiên bô câu hỏi.

+ Tiêu chuẩn loại trừ: Bệnh nhân tự ý bỏ điều trị.

\subsection{Phương pháp nghiên cứu}

2.2.1. Thiết kế nghiên cứu: Nghiên cứu tiến cứu, mô tả cắt ngang.

2.2.2. Cỡ mẫu nghiên cứu: 150 bệnh nhân

2.2.3. Chỉ tiêu nghiên cứu

+ Chỉ tiêu về lâm sàng: tuổi, giới, nghề nghiệp, thời gian mắc, hoàn cảnh xuất hiện.

+ Chỉ tiêu về phân loại và điêu trị: triệu chứng lâm sàng trước và sau điều trị về: mức độ đau (VAS), độ giãn cột sống thắt lưng, khoảng cách tay đất, phương pháp điều trị, kết quả điều trị

2.3. Thời gian và địa điểm nghiên cứu: nghiên cứu được tiến hành từ tháng 01/2019 đến tháng 09/2019 tại phòng Châm cứu ngoại trú - Bệnh viện Đa khoa YHCT Hà Nội.

2.4. Thu nhập và xử lý số liệu: Số liệu được xử lý bằng phần mềm STATA 13.0 với các thuật toán, tính các tỉ lệ, giá trị trung bình, độ lệch chuẩn SD.

\section{KẾT QUẢ NGHIÊN CứU}

\section{1. Đăc điểm lâm sàng của bênh nhân}

Bảng 3.1: Phân bố bệnh nhân theo tuổi và giớí

\begin{tabular}{|c|c|c|}
\hline Độ tuối & $\mathbf{n ~ ( 1 5 0 )}$ & $\mathbf{\%}$ \\
\hline $18-29$ & 20 & 13,33 \\
\hline $30-39$ & 51 & 34,0 \\
\hline $40-49$ & 33 & 22,0 \\
\hline $50-59$ & 29 & 19,33 \\
\hline$\geq 60-69$ & 17 & 11,34 \\
\hline Tuô̂i trung bình & $42,66 \pm 12,8$ & \\
\hline Giới tính & $\mathbf{n ~ ( 1 5 0 )}$ & $\mathbf{\%}$ \\
\hline Nam & 54 & 36 \\
\hline Nữ & 96 & 64 \\
\hline
\end{tabular}

Nhóm tuối từ 30 - 39 tuổi chiếm tỉ lệ cao nhất (34,0\%). Độ tuổi trung bình là 42,66 $\pm 12,8$.
Bảng 3.2. Phân bố bệnh nhân theo nghề nghiệp, thời gian mắc bệnh và hoàn cảnh xuất hiên bênh

\begin{tabular}{|c|c|c|}
\hline Nghề nghiệp & $\mathbf{n ~ ( 1 5 0 )}$ & $\mathbf{\%}$ \\
\hline Lao động trí óc & 87 & 58 \\
\hline Lao động tay chân & 48 & 32 \\
\hline Tự do & 15 & 10 \\
\hline Thời gian mắc bệnh & $\mathbf{n ~ ( 1 5 0 )}$ & $\mathbf{\%}$ \\
\hline$<4$ tuần & 108 & 72 \\
\hline $4-12$ tuần & 31 & 20,67 \\
\hline$>12$ tuần & 11 & 7,33 \\
\hline $\begin{array}{c}\text { Hoàn cảnh xuất } \\
\text { hiện }\end{array}$ & $\mathbf{n ~ ( 1 5 0 )}$ & $\mathbf{\%}$ \\
\hline Thay đối thời tiết & 77 & 51,33 \\
\hline Vận động sai tư thế & 10 & 6,67 \\
\hline Sau chấn thương & 63 & 42 \\
\hline Tậ bênh nhan nứ can
\end{tabular}

Tỉ lệ bệnh nhân nữ cao hơn nam (nữ: 64,0\%; nam $36,0 \%)$. Chủ yếu bênh xuất hiện ở nhóm lao động trí óc (58\%). Đa số bệnh nhân thời gian mắc bệnh < 4 tuần (72,0\%). Bệnh xuất hiện thường sau khi thay đổi thời tiết (51,33\%).

3.2. Tình hình điêu trị đau thắt lưng

Bảng 3.3 Sự thay đổi triệu chứng lâm sàng sau điêu tri

\begin{tabular}{|c|c|c|c|}
\hline Nhóm & $\begin{array}{l}\text { Trước } \\
\text { điều trị }\end{array}$ & $\begin{array}{c}\text { Sau } \\
\text { điều trị }\end{array}$ & Ps-T \\
\hline Chỉ số & $\bar{X} \pm \mathrm{SD}$ & $\bar{X} \pm \mathrm{SD}$ & \\
\hline VAS (điểm) & $\begin{array}{c}5,71 \pm \\
1,24\end{array}$ & $\begin{array}{c}1,75 \pm \\
1,26\end{array}$ & $\begin{array}{c}< \\
0,05\end{array}$ \\
\hline $\begin{array}{l}\text { Khoảng cách } \\
\text { tay đất (cm) }\end{array}$ & $\begin{array}{c}11,93 \pm \\
11,66\end{array}$ & $\begin{array}{c}4,41 \pm \\
5,88\end{array}$ & 0,05 \\
\hline Schöber (cm) & $\begin{array}{c}0,4 \pm \\
0,91\end{array}$ & $\begin{array}{c}4,06 \pm \\
0,6\end{array}$ & 0,05 \\
\hline
\end{tabular}

Các triệu chứng lâm sàng được cải thiện có ý nghĩa thống kê với $\mathrm{p}<0,05$.

Bảng 3.4: Phương pháp điều trị chung

\begin{tabular}{|c|c|c|}
\hline Phương pháp điêuu trị & $\mathbf{n}$ & $\mathbf{\%}$ \\
\hline YHCT & 2 & 1,33 \\
\hline YHCT kết hợp YHHĐ & 148 & 98,67 \\
\hline Tống & $\mathbf{1 5 0}$ & $\mathbf{1 0 0 , 0}$ \\
\hline
\end{tabular}

Tỷ lệ bệnh nhân điều trị YHCT kễt hợp YHHĐ chiếm đảa số.

Bảng 3.5: Phương pháp điều trị dùng thuốc và không dùng thuốc

\begin{tabular}{|c|c|c|c|c|}
\hline \multirow{2}{*}{\multicolumn{2}{|c|}{ Phương pháp }} & & \multicolumn{2}{|c|}{ Đối tương NC } \\
\hline & & & \multirow{2}{*}{$\begin{array}{c}\mathbf{n} \\
18 \\
\end{array}$} & \multirow{2}{*}{$\begin{array}{c}\% \\
12,0\end{array}$} \\
\hline \multirow{5}{*}{ YHHĐ } & \multirow{4}{*}{ Dùng thuốc } & & & \\
\hline & & \begin{tabular}{|c|} 
Điêu trị cụ thể \\
Giảm đau chống viêm \\
Giãn cơ
\end{tabular} & 16 & 10,67 \\
\hline & & Chống thoái hóa & 5 & 3,33 \\
\hline & & Loãng xương & 7 & 4,67 \\
\hline & Không dùng thuốc & Chiếu đèn hông ngoại & 148 & 98,67 \\
\hline \multirow{4}{*}{ YHCT } & \multirow{2}{*}{ Dùng thuốc } & Thuốc sắc & 3 & 2,0 \\
\hline & & Thuốc tán & 1 & 0,67 \\
\hline & \multirow{2}{*}{ Không dùng thuốc } & Điện châm & 150 & 100,0 \\
\hline & & Xoa bóp bấm huyệt & 149 & 99,33 \\
\hline \multicolumn{3}{|c|}{ Thủy châm } & 15 & 10,0 \\
\hline
\end{tabular}


Đa số bênh nhân được điều trị bằng các phương pháp không dùng thuốc của YHHĐ là chiếu đèn hồng ngoại $(98,67 \%)$ và của $\mathrm{YHCT}$ là điện châm (100\%), xoa bóp bấm huyệt (99,33\%).

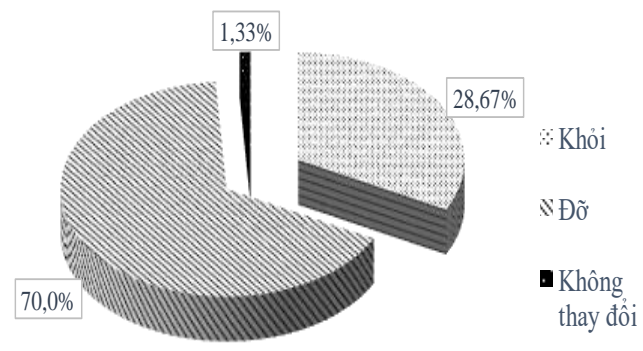

Biểu đồ 3.1: Kêt quả điều trị chung

Trong số những bệnh nhân đến khám và điêu trị, tỉ lệ bệnh nhân đỡ cao $(70,0 \%)$ và khỏi (28,67\%). Không có bệnh nhân nào nặng thêm.

\section{BÀN LUÂ̂N}

Độ tuổi trung bình bệnh nhân ĐTL trong nghiên cứu gặp chủ yếu ở độ tuổi lao động. Do đặc thù phòng Châm cứu ngoại trú thường tiếp nhận các bệnh nhân không có thời gian nằm điều trị nội trú. Trong một số nghiên cứu của các tác giả trước đây, ĐTL rất ít gặp ở bệnh nhân trẻ tuổi, nhưng hiện nay ĐTL có xu hướng ngày càng trẻ hóa, do cuộc sống phát triển gắn liền với công nghệ. Việc sử dụng máy tính, điện thoại nhiều giờ, thói quen sinh hoạt không hợp lí, ít vận động nên thoái hóa cột sống xảy ra sớm. Trong nghiên cứu, tỉ lệ bệnh nhân ĐTL là nữ chiếm phần lớn (64\%). Nữ giới ở ngoài 30 tuổi, mât độ xương giảm dần (mỗi năm giảm 0,25 đển $1 \%$ ). Hơn nữa với quá trình mang thai, sinh đẻ cũng ảnh hưởng không tốt đến cột sống thắt lưng. Sau khi mãn kinh, lượng ostrogen giảm mạnh làm tăng tốc độ hủy xương; sự hấp thu canxi và tổng hợp các vitamin cũng kém đi ảnh hưởng đến cấu trúc của xương, sụn [6]. ĐTL là bệnh liên quan mật thiết đến nghề nghiệp. Những người làm việc nặng nhọc, thường xuyên bê vác nặng hay những nhân viên văn phòng ngồi lâu hàng giờ đều dễ xảy ra đau thắt lưng. Thời gian mắc bệnh dưới 4 tuần chiếm tỉ lệ caoo nhất $(72,0 \%)$. Kết quả tương đồng với Nguyễn Minh Giang thời gian mắc bệnh từ 7 ngày đến 3 tháng $(45,0 \%)$ [ 2]. Bệnh nhân xuất hiện ĐTL do thay đổi thời tiết và vận động sai tư thế chiếm tỉ lệ cao $(51,33 \%$ và $42,0 \%)$.

Sau quá trình điêu trị, các đặc điểm lâm sàng bệnh nhân cải thiện rõ rệt. Đối tượng nghiên cứu của chúng tôi đa phần sống ở thành thị, trong độ tuổi lao động và ít mắc bệnh nặng và phối hợp. Khi bắt đầu xuất hiện các triệu chứng, bệnh nhân thường đi khám, điều trị sớm. Hơn nữa các bệnh nhân đa số đều được kết hợp điều trị bằng phương pháp YHCT kết hợp YHHĐ (chiểm tới $98,67 \%$ ). Kết quả này tương đồng với Trần Thị Đài Trang (2018) tỉ lệ bệnh nhân được điều trị kết hợp YHCT và YHHĐ chiếm tới 93,2\% [5]; Nguyến Minh Giang (2015) tại viện YHCT Trung Ương thì tỉ lệ này là 95,9\% [2]. Như vậy, sự kết hợp giữa YHHD và YHCT đã mang lại hiệu quả điều trị tốt nhất cho bệnh nhân, và đây cũng là phương châm của các bệnh viện YHCT. Hầu hết bệnh nhân được sử dụng các phương pháp không dùng thuốc của YHHD và YHCT, 100\% bênh nhân sử dung điên châm, 99,33\% bênh nhân được xoa bóp bấm huyệt và $98,67 \%$ bệnh nhân chiếu đèn hồng ngoại vùng thắt lưng. Kết quả này tương đồng với Nguyễn Minh Giang (2015) có $94,1 \%$ bệnh nhân điện châm, $66,8 \%$ xoa bóp bấm huyệt và $68,6 \%$ chiếu đèn hồng ngoại [2]; Trần Thị Đài Trang (2018) với 98,6\% bệnh nhân điện châm [5]. Đây đều là những phương pháp không dùng thuốc được sử dụng phổ biến, ít có tác dụng phụ. Trong đó điện châm là phương pháp được sử dụng nhiều nhất và mang lại hiệu quả cao. Theo Louise Chang (2007) đánh giá tác dụng giảm đau của điện châm đơn thuần với ĐTंL cho thấy $33 \%$ có cải thiện triệu chứng đau, $12 \%$ cải thiện chức năng hoạt động [7]. Để tăng tác dụng điều trị, hiện nay trên lâm sàng thường phối hợp điện châm và xoa bóp bấm huyệt. Trong nghiên cứu, hầu hết các bênh nhân đêu khỏi và đỡ (khỏi $28,67 \%$; đõ $70,0 \%$ ); không có ai nặng thêm. Điều này chứng tỏ việc điều trị bệnh nhân ĐTL tại đây rất hợp lý nhờ sự kết hợp nhuần nhuyễn giữa các phương pháp YHCT và YHHĐ. Kết quả này tương đồng với Trần Thị Đài Trang kết quả đõ 62,1\%, khỏi hoàn toàn $37,7 \%[5]$.

\section{KẾT LUÂN}

1. Tuổi trung bình trong nghiên cứu là 42,66 $\pm 12,8$. Tỉ lê nữ cao hơn nam $(64,0 \%)$. Phần lớn bệnh nhân là lao động trí óc $(58,0 \%)$. Thời gian mắc bệnh chủ yễu $<4$ tuần $(72,0 \%)$. Bệnh thường xuất hiện sau thay đổi thời tiết (51,33\%)

2. Bênh nhẩn được điêu trị kết hợp YHHĐ và YHCT (98,67\%). 100\% bệnh nhân sử dụng các phương pháp không dùng thuốc của YHHĐ và YHCT. Kết quả điều trị, tî lệ bệnh nhân đõ cao (70,0\%).

TÀI LIỆU THAM KHẢO

1. Trân Ngọc Ân (2002). Bệnh thấp khớp-NXB Y học. 
2. Nguyễn Minh Giang (2015). Khảo sát các thể lâm sàng $Y$ học cổ truyền và tình hình điều trị đau thắt lưng tại bệnh viện $Y$ học cổ truyền trung ương, Luận văn tốt nghiệp bác sỹ y khoa, Đại học Y Hà Nôi.

3. Trân Quốc Hùng, Nguyễn Thị Thanh Tú và công sư (2018), Khảo sát mô hình bênh tât và tình hình điều trị tại phòng Châm cứu ngoại trú bênh viên đa khoa YHCT Hà Nôi, Đề tài nghiên cứu khoa học cấp cơ sở năm 2018, Bệnh viện Đa khoa YHCT Hà Nôi.

4. Nguyễn Thị Ngọc Lan (2016), Bệnh học cơ
Xương khớp nội khoa, Nhà xuất bản giáo dục Việt Nam, tr 138 - 162.

5. Trân Thị Đài Trang, Lê Thành Xuân, Trân Phương Đông (2018), Khảo sát phân thể lâm sàng và hiệu quá điều trị đau vùng thắt lưng tại Bênh viện Châm cứu Trung Ương, Tạp chí Y học Viêt Nam, tập 468; Tháng 7; Số 1; năm 2018, tr $155-159$.

6. National Institutes of Health (2011), Dietary supplement fact sheet: Calcium, 11 (4), $175-182$.

7. Louise Chang M.D (2007), Study: Acupuncture Eases Low Back Pain, WedMD Health News.

\section{ĐO LƯờ'NG SÃ̃N SÀNG CHI TRẢ ĐỐI VỚI XÉT NGHIÊM SÀNG LOQC UNG THƯ ĐẠI TRỰC TRÀNG TẠI VIỆT NAM}

\section{TÓM TẮT}

Mục tiêu: Ước tính mức sẵn sàng chi trả đối với xét nghiệm tìm máu ẩn trong phân (FOBT) và nội soi đại trực tràng để sàng lọc ung thư đại trực tràng tại Viêt Nam. Phương pháp: Sử dung phương pháp lượng giá ngẫu nhiên phụ thuộc với thiêt kế câu hỏi là câu hỏi có - không hai mức nhằm ước tính sằn sàng chi trả đối với xét ngiệm tìm máu ẩn trong phân và̀ nôi soi đai trực tràng trên 402 đối tương là khách hàng từ $50-75$ tuổi đển khám bênh thông thường tai các phòng khám bênh ngoại trú thuộc Trung tâm y tế quân Hoàn Kiếm từ tháng 1 đến tháng 3 năm 2019. Kết quả và kết luận: Có $7,2 \%$ đối tượng tham gia nghiên cứu từ chối chi trả tiền túi để thực hiện sàng loc ung thư đai trực tràng sử dung xét nghiêm tìm máu ẩn trong phân FOBT hay nội soi đại trực tràng. Giá tri trung bình và trung vị sẵn sàng chi trả đối với xét nghiệm tìm máu ẩn trong phân FOBT lần lượt là 459.650 đồng (95\%KTC: $402.410 ; 548.660)$ và 335.220 đồng (95\%KTC: 303.810; 372.280). Tương tư như vây giá trị trung bình và trung vị sẵn sàng chi trả đối với nôi soi đaii trực tràng lân lướt là 752.300 đồng (95\%KTC: $690.050 ; 831.750)$ và 582.000 đồng (95\%KTC: 537.600; 627.300).

Tư khóa: Sẵn sàng chi trả, đo lường sự ưa thích lý thuyết, phương pháp lượng giá ngẫu nhiên phụ thuộc

\section{SUMMARY \\ WILLINGNESS TO PAY FOR COLORECTAL CANCER SCREENING IN VIETNAM}

Objective: To estimate willingness to pay for Fecal Occult Blood Test (FOBT) and colonoscopy for colorectal cancer screening in Vietnam. Method: Employing contigent valuation method with doublebounded question design to estimate willingness to

*Trường Đại họ Y tế Công Công

Chịu trách nhiệm chính: Nguyễn Quỳnh Anh

Email: nqa@huph.edu.vn

Ngày nhận bài: 3.3 .2021

Ngày phản biên khoa hoc: 28.4.2021

Ngày duyệt bài: 12.5 .2021

\section{Nguyễn Quỳnh Anh*, Nguyễn Thu Hà*}

pay for FOBT and colonoscopy. We surveyed 402 patients aged 50-75 years old who goes to the outpatient clinics of Hoan Kiem District Medical Center from January to March 2019. Results and conclusion: $7.2 \%$ of study participants refused to pay out-of-pocket to perform colorectal cancer screening using either the FOBT or colonoscopy. Mean and median willingness-to-pay values for the FOBT were 459,650 VND (95\% CI: 402,410; 548,660) and 335,220 VND (95\% CI: 303,810; 372,280). Similarly, the mean and median willingness to pay values for colonoscopy were VND 752,300 (95\% CI: 690,050 831,750 ) and VND 582,000 (95\% CI: 537,600; 627,300).

Keywords: Willingness to pay, stated preference, contigent valuation, WTP, CV

\section{I. ĐĂT VẤN ĐỀ}

Ung thư đại trực tràng (UTĐTT) là ung thư phổ biến thứ ba ở nam giới và phổ biến thứ hai ở nữ giới [1]. Tại Việt Nam, 14,733 trường hợp mới mắc UTĐTT được ướ tính vào năm 2018. Việc đầu tư cho sàng loc UTĐTT ở Việt Nam đã được khẳng định về mặt chủ trương thông qua phể duyệt của Dư án chủ động dự phòng, phát hiên sớm, chẩn đoán, điều trị, quản lý bênh ung thư, tim mach, đái tháo đường, bênh phổi tắc nghẽn mạn tính, hen phế quản và các bệnh không lây nhiễm khác, giai đoạn 2016-2020. Các biện pháp sàng lọc được Bộ Y tế khuyến cáo đối với UTĐTT là thực hiện xét nghiệm máu ẩn trong phân (FOBT) và sàng lọc UTĐTT với trường hợp kết quả + và với các trường hợp có nguy cơ cao. Tuy nhiên, đến thời điểm hiên tại, sàng lọc UTĐTT ở Việt Nam mới chỉ diển ra thí điểm ở một số tỉnh thành phố lớn và chưa triển khai được các hoat động chi tiết như được mô tả trong các quyết định này.

Để có thể triển khai được chương trình sàng lọc UTĐTT một cách hiệu quả tại Việt Nam, việc 